\title{
Tegillarca granosa extract Haishengsu inhibits tumor activity via a mitochondrial-mediated apoptotic pathway
}

\author{
XUE-HONG CHEN ${ }^{1}$, YAN-TAO HAN ${ }^{1}$, JUN-LI YE $^{1}$, ZHI-SHANG CHANG $^{1}$, \\ CHUN-BO WANG ${ }^{1}$ and SHOU-GUO CHEN ${ }^{2}$
}

\author{
${ }^{1}$ Department of Pharmacology, Basic Medical College, Qingdao University, Qingdao, Shandong 266071; \\ ${ }^{2}$ Department of Technology, Qingdao Haihui Biochemical Pharmaceutical Company, Qingdao, Shandong 266031, P.R. China
}

Received December 24, 2015; Accepted January 27, 2017

DOI: $10.3892 / \mathrm{mmr} .2018 .8654$

\begin{abstract}
Haishengsu (HSS) is an active natural extract isolated from Tegillarca granosa, which has previously been demonstrated to inhibit the proliferation of several types of cancer cells in vitro. Our previous study indicated that HSS may induce apoptosis to suppress growth of human hepatocellular carcinoma BEL-7402 cells by activating Fas pathway. The present study demonstrated that HSS treatment induces the in vitro apoptosis of BEL-7402 cells via the mitochondrial-mediated apoptotic pathway detected by DNA fragmentation assay, caspase activity assay and transmission electron microscopy assay, and inhibits tumor xenograft growth in vivo. Alterations in apoptotic regulatory proteins were detected, including decreased expression of B-cell lymphoma2 (Bcl-2), upregulation of Bcl-2-associated X protein and mitochondrial cytochrome $c$ release, and downstream activation of apoptotic signaling. Furthermore, apoptotic induction was caspase-dependent, as indicated by cleavage of the caspase substrate, poly (ADP-ribose) polymerase. Oral administration of $62.5-250 \mathrm{mg} / \mathrm{kg}$ HSS markedly educed the growth of hepatocellular carcinoma tumor xenografts in nude mice. In addition, immunohistochemical staining for caspase-3 protein and transmission electron microscopy further indicated the induction of apoptosis in these tumor tissues. Taken together, the present study demonstrated that HSS may effectively induce apoptosis to suppress the growth of BEL-7402 cells in vitro and in vivo, and therefore may hold promise for further development as a novel cancer therapy.
\end{abstract}

\section{Introduction}

The ocean covers $\sim 70 \%$ of the Earth's surface; it is a rich source of natural resources and contains $\sim 80 \%$ of all the biodiversity

Correspondence to: Professor Xue-Hong Chen or Professor Yan-Tao Han, Department of Pharmacology, Basic Medical College, Qingdao University, 308 Ningxia Road, Qingdao, Shandong 266071, P.R. China E-mail: chen-xuehong@163.com

E-mail: hanyt19@126.com

Key words: Haishengsu, BEL-7402 cells, apoptosis, mitochondrialmediated apoptotic pathway, apoptosis-related proteins, xenografts on our planet. It is home to approximately one million multicellular species and one billion unicellular species (1). During the past 30-40 years, $>22,000$ novel natural products have been identified from marine sources, whereas $\sim 131,000$ have been identified from terrestrial sources. These marine products have various biological properties, including anticancer and antiviral activities $(2,3)$. The study of anticancer marine natural products (MNPs) is an important approach to global drug discovery. MNPs have featured significantly in the development of anticancer drugs; furthermore, they are generally free of deleterious side effects and are usually inexpensive (4).

A large proportion of MNPs have been extracted from marine invertebrates, including alkaloids, peptides, terpenes and polyketides (5,6). Tegillarca granosa is a type of marine invertebrate widely distributed in China, which has been a traditional Chinese seafood for hundreds of years. Haishengsu (HSS) is an extract isolated from T. granosa, and its major chemical constituents are small molecular weight proteins that rangebetween 15 and $23 \mathrm{kDa}$. Previous clinical and experimental studies regarding HSS have investigated its anticancer properties, and the possible mechanisms associated with its activity. Clinical studies have indicated that HSS, used in combination with other chemotherapeutic agents, may display significant activity against human cancers, such as non-small-cell lung cancer and advanced renal cell cancer; therefore, it may have the potential to improve the quality of life for these patients $(7,8)$. Experimental studies have demonstrated that HSS may have an inhibitory effect on several human cancer cells, including ovarian cancer cell lines (SKOV-3 and OVCAR-3), lung carcinoma cell lines (A549 and NCI-H292), leukemia cell lines (K562 and K562/ADM) and renal carcinoma cell lines (OS-RC-2) (9-13). Furthermore, murine studies have indicated that HSS may inhibit the growth of Ehrlich ascites tumors and improve immunological functions (14). Our previous study demonstrated that HSS was able to induce the apoptosis of human hepatocellular carcinoma (HCC) cells in a concentration-dependent manner, through the Fas signaling pathway, with caspase- 8 and caspase- 3 activation (15).

As a type of programmed cell death, apoptosis is a genetically controlled suicide mechanism that enables organisms to control cell number and eliminate cells that threaten survival (16). Classical apoptosis can be initiated via two major pathways: The intrinsic or mitochondrial-mediated pathway, 
and the extrinsic or death receptor-mediated pathway (17). A study from our laboratory indicated that HSS induces apoptosis in HCCBEL-7402 cells via the Fas signaling pathway (15). However, little is currently known regarding the mechanisms responsible for the mitochondrial-mediated apoptotic pathway of HSS against HCC cells. The present study further investigated whether mitochondrial-mediated apoptotic pathways are involved in the inhibitory effects of HSS on BEL-7402 cells, with the aim of providing further experimental evidence to support the HSS-based treatment of HCC.

\section{Materials and methods}

HSS preparation. HSS was extracted from the shellfish Tegillarca granosa as described previously (15), and dissolved in phosphate-buffered saline (PBS) prior to use.

Cell culture. The human HCC cell line BEL-7402 was obtained from the Shanghai Cell Bank at the Institute of Biochemistry and Cell Biology (Chinese Academy of Sciences, Shanghai, China). Cells were maintained in RPMI 1640 medium (GE Healthcare, Chicago, IL, USA) supplemented with $10 \%$ (v/v) fetal bovine serum (GE Healthcare), $100 \mathrm{U} / \mathrm{ml}$ penicillin and $100 \mathrm{mg} / \mathrm{ml}$ streptomycin, under $5 \% \mathrm{CO}_{2}$ at $37^{\circ} \mathrm{C}$, in a humidified incubator.

DNA fragmentation assay. DNA fragmentation is a marker of cell apoptosis (18). Briefly, BEL-7402 cells were treated with various concentrations $(0-100 \mu \mathrm{g} / \mathrm{ml})$ of $\mathrm{HSS}$ for $48 \mathrm{~h}$ at $37^{\circ} \mathrm{C}$. Subsequently the cells were centrifuged $\left(500 \mathrm{x}\right.$ g for $5 \mathrm{~min}$ at $\left.4^{\circ} \mathrm{C}\right)$ and washed with PBS, and the pellets were then resuspended in $500 \mu \mathrm{l}$ cell lysis buffer $[150 \mathrm{mM} \mathrm{NaCl}, 10 \mathrm{mM}$ Tris- $\mathrm{HCl}$ (pH 7.5), $10 \mathrm{mM}$ EDTA, 0.5\% SDS, $500 \mathrm{mg} / 1$ proteinase $\mathrm{K}$ ] and incubated overnight at $50^{\circ} \mathrm{C}$. Following incubation, the cell lysate was extracted with phenol/chloroform/isopropyl alcohol $(25: 24: 1 \mathrm{v} / \mathrm{v})$, the DNA was precipitated with sodium acetate (50 $\mu \mathrm{l} ; 3 \mathrm{M}, \mathrm{pH} 5.2)$ and ethanol $(1 \mathrm{ml})$ at $-20^{\circ} \mathrm{C}$ overnight, and subsequently washed with $70 \%$ ethanol. The DNA pellet was dissolved in Tris-EDTA buffer $(10 \mathrm{mM}$ Tris, $1 \mathrm{mM}$ EDTA, $\mathrm{pH} 8.0)$ and incubated with RNase A $(20 \mu \mathrm{g} / \mathrm{ml})$ at $37^{\circ} \mathrm{C}$ for $30 \mathrm{~min}$. Subsequently, DNA samples were separated by horizontal electrophoresis on $1.5 \%$ agarose gels, stained with ethidium bromide, and visualized under UV light.

Caspase activity assay. The activities of caspase-3 and -9 were detected using a Caspase Colorimetric Assay kit (cat. nos. ab39401 and ab65608; Abcam, Cambridge, UK), according to the manufacturer's protocol. Caspase activity was measured via the cleavage of chromogenic caspase substrates. Briefly, following treatment with various concentrations $(0-100 \mu \mathrm{g} / \mathrm{ml})$ of HSS for $48 \mathrm{~h}$ at $37^{\circ} \mathrm{C}$, BEL-7402 cells were harvested and lysed in the supplied lysis buffer. The lysed cells were centrifuged at $18,000 \mathrm{x} g$ for $10 \mathrm{~min}$, and protein concentrations were determined using a bicinchoninic acid assay. The proteins were mixed with caspase substrates at $37^{\circ} \mathrm{C}$ for $2 \mathrm{~h}$, and the p-nitroaniline light emission was quantified using a microplate reader at $405 \mathrm{~nm}$.

Western blot analysis. After treatment, cells were harvested and lysed with ice-cold lysis buffer (Cell Signaling Technology, Inc., Danvers, MA, USA) containing protease inhibitors
(Sigma Aldrich, Merck KGaA, Darmstadt, Germany). The mitochondrial and cytosolic proteins were extracted using a Cell Mitochondria Isolation kit (Beyotime Biotechnology, Haimen, China) according to the manufacturer's protocol. Briefly, the cell pellet was then resuspended in the extraction buffer which was enclosed in the isolation kit. After $30 \mathrm{~min}$ incubation on ice, cells were homogenized with a dounce homogenizer, and the homogenate was centrifuged at $600 \mathrm{xg}$ for $10 \mathrm{~min}$ at $4^{\circ} \mathrm{C}$. The supernatant was spun at $11,000 \mathrm{x} \mathrm{g}$ for $10 \mathrm{~min}$ at $4^{\circ} \mathrm{C}$. The supernatant (cytosolic fraction) was removed and maintained at $-80^{\circ} \mathrm{C}$. The pellet containing mitochondria was resolved in the lysis buffer which was enclosed in the isolation kit. The protein concentration was determined using the bicinchoninic acid assay (Beyotime Biotechnology). Western blotting was performed as previously described (19). Extracted proteins $(50 \mu \mathrm{g})$ in lysates were separated by $10-12 \%$ SDS-PAGE and then transferred electrophoretically onto polyvinylidene difluoride membranes (EMD Millipore, Billerica, MA, USA). Membranes were blocked with 5\% non-fat milk overnight at $4^{\circ} \mathrm{C}$. Subsequently, membranes were stained with primary antibodies against poly (ADP-ribose) polymerase (PARP; 1:1,000), caspase-9 (1:1,000), caspase-3 (1:100), B-cell lymphoma 2 (Bcl-2; 1:500), Bcl-2-associated X protein (Bax; 1:1,000), cytochrome $c$, cytochromecoxidase (COX)-IV (1:100), $\alpha$-tubulin $(1: 5,000)$, (cat. nos. ab4830, ab32539, ab4051, ab59348, ab32503, ab14744 and ab7291 respectively; Abcam). A rabbit polyclonal antibody to GAPDH was used as a loading control (1:500; cat. no. ab8245). Bands were detected with SuperSignal West Femto Maximum Sensitivity substrate (Pierce; Thermo Fisher Scientific, Inc.) and imaged with the ChemiDoc $^{\mathrm{TM}}$ MP Imaging system (Bio-Rad Laboratories, Inc., Hercules, CA, USA). Densitometry analysis was performed using Quantity One analysis software (version 4.6.9; Bio-Rad Laboratories, Inc.).

In vivo antitumor efficacy. Female $\mathrm{BALB} / \mathrm{c}$ nude mice (6-8 weeks of age, weight 18-22 g) were provided by the Laboratory Animal Institute, Chinese Academy of Medical Sciences (Beijing, China). Animal experiments were performed in accordance with the Chinese Animal Protection Network, and laboratory protocols were approved by the Animal Care and Use Committee of Qingdao University (Qingdao, China). The mice were housed in cages in a room with an artificial 12 -h light/dark cycle at a constant temperature range $\left(24 \pm 2^{\circ} \mathrm{C}\right)$ and relative humidity $(55 \pm 10 \%)$. The mice were acclimated for one week prior to the study, and fed standard chow and water ad libitum. In particular, mice were maintained in specific-pathogen-free-conditions. Animals were subjected to surgical procedures in accordance with Institutional guidelines. Tumors were established by subcutaneous injection of $2 \times 10^{6}$ BEL-7402 cells into the flank. Tumor volumes were estimated according to the formula: Tumor volume $\left(\mathrm{mm}^{3}\right)=\left(\right.$ length $\mathrm{x}$ width $\left.{ }^{2}\right) / 2$. When tumors reached a size of $\sim 100 \mathrm{~mm}^{3}$, the mice were randomly assigned to 4 groups ( $n=6 /$ group): Control and 3 treatment groups. The mice in the HSS-treatment groups were intragastrically administrated $0.5 \mathrm{ml}$ HSS daily, at doses of $62.5,125$ or $250 \mathrm{mg} / \mathrm{kg}$ in a solution containing $0.5 \%$ sodium carboxymethylcellulose. The vehicle treated control mice received $0.5 \%$ sodium carboxymethylcellulose. The mice were monitored closely 
and weighed twice a week. The mice were sacrificed 26 days and then tumor xenografts, liver and kidney samples were collected for the following experiments.

Transmission electron microscopy (TEM) assay. Tumor tissues from HSS-treated mice were examined using transmission electron microscopy. Briefly, $1 \mathrm{~mm}^{3}$ tumor tissue sections were fixed in $4 \%(\mathrm{w} / \mathrm{v})$ glutaraldehyde followed by $1 \%(\mathrm{w} / \mathrm{v})$ osmic tetroxide, and then embedded in epoxy resin. Serial $0.5 \mu \mathrm{m}$ sections were sliced and stained with uranyl acetate-lead citrate, and examined under an $\mathrm{H}-7650$ transmission electron microscope at $80 \mathrm{kV}$ (Hitachi, Ltd., Tokyo, Japan).

Histological evaluations. Tissue sections $(4 \mu \mathrm{m})$ were generated from the paraffin-embedded tissue specimens, and were stained with hematoxylin and eosin (H\&E). Endogenous peroxidase activity was blocked with $3 \% \mathrm{H}_{2} \mathrm{O}_{2}$ in methanol at room temperature for $15 \mathrm{~min}$ after deparaffinization and rehydration. Antigen retrieval was performed by heating the slides in $0.01 \mathrm{M}$ sodium citrate buffer at $95^{\circ} \mathrm{C}$ for $3 \mathrm{~min}$. After blocking with $10 \%$ bovine serum albumin in PBS for $60 \mathrm{~min}$, the slides were incubated with a primary antibody against caspase-3 (1:10; cat. no. ab4051; Abcam) at $4^{\circ} \mathrm{C}$ overnight. After three washes in PBS, the slides were incubated with horseradish peroxidase-conjugated secondary antibodies (1:200; cat. no. ab6728; Abcam). The immune complex was visualized using 3,3'-diaminobenzidene-chromogen (Dako; Agilent Technologies, Inc., Santa Clara, CA, USA) according to the manufacturer's protocol. Counterstaining was performed on representative sections with hematoxylin, and then the slides were observed under a light microscope (Olympus Corporation, Tokyo, Japan). Quantitative analysis was performed using Image-Pro Plus software (version 4.5; Media Cybernetics, Inc., Rockville, MD, USA).

Statistical analysis. Statistical analyses were performed with SPSS 13.0 (SPSS, Inc., Chicago, IL, USA). All data were presented as the mean \pm standard deviation. The differences between groups were evaluated using one-way analysis of variance followed by Student Newman-Keuls test. $\mathrm{P}<0.05$ is considered to indicate a statistically significant difference.

\section{Results}

HSS induces apoptosis of BEL-7402 cells. Our previous research demonstrated that HSS induces apoptosis of BEL-7402 cells, as determined by flow cytometric analysis and Hoechst 33258 nuclear staining (15). To further confirm these results, a DNA fragmentation assay was conducted, since DNA fragmentation is a classical hallmark of apoptosis. Apoptosis of BEL-7402 cells was observed following treatment with HSS for $48 \mathrm{~h}$ at 25,50 and $100 \mu \mathrm{g} / \mathrm{ml}$. HSS treatment resulted in increased DNA fragmentation in BEL-7402 cells, when treated with increasing HSS concentrations (Fig. 1). These results indicated that HSS exhibited a significant apoptosis-inducing effect on BEL-7402 cells.

HSS induces caspase activation in BEL-7402 cells. Activation of the caspase cascade is an important mechanism in apoptotic cell death in most cell systems (20). The enzymatic activities

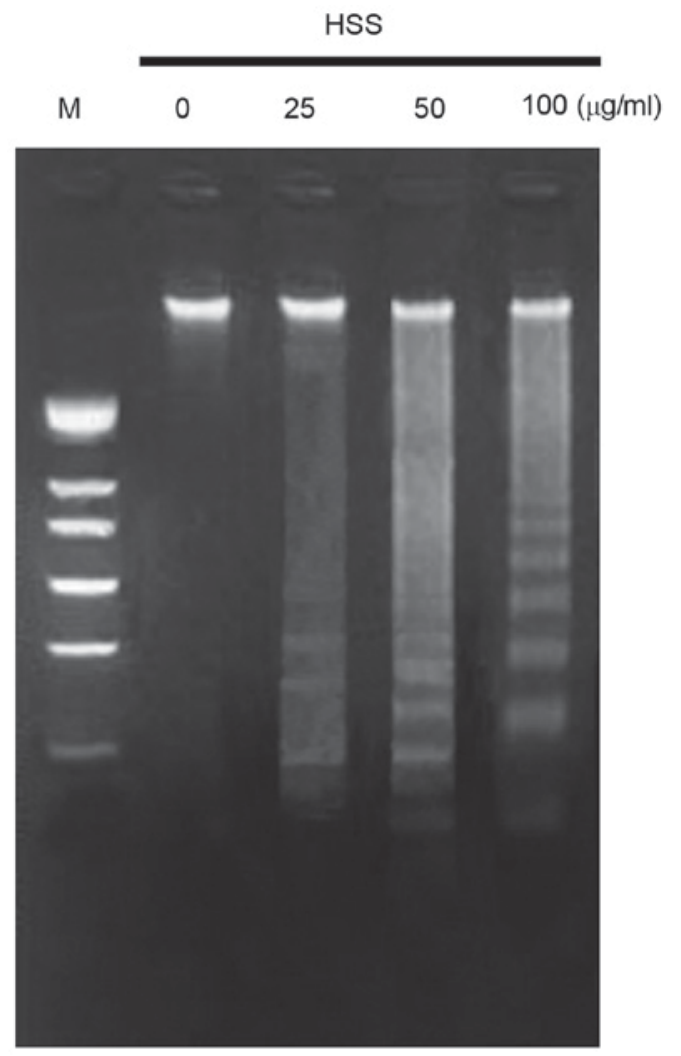

Figure 1. HSS induces DNA fragmentation in hepatocellular carcinoma-derived BEL-7402 cells. Cells were pretreated with $0,25,50$ or $100 \mu \mathrm{g} / \mathrm{ml}$ HSS for $48 \mathrm{~h}$, and DNA fragmentation was analyzed by agarose gel electrophoresis. Results are representative of three independent experiments. M, DNA markers of 2 and 1 kb, 750, 500 and 200 bp; HSS, Haishengsu.

of caspase- 3 and caspase- 9 were detected using a Caspase Colorimetric Assay kit. Following treatment with HSS, the enzymatic activities of caspase- 3 and caspase- 9 were significantly increased (Fig. 2A). The relative activities of caspase-3 and caspase- 9 were increased to $2.438 \pm 0.219(\mathrm{P}<0.01)$ and $1.834 \pm 0.163(\mathrm{P}<0.01)$, respectively, following treatment with $100 \mu \mathrm{g} / \mathrm{ml}$ HSS. To further confirm the role of caspase, western blot analysis was performed to detect the protein levels of caspase- 3 and caspase-9. In agreement with the caspase activity assay results, caspase- 9 activation accompanied the proteolytic degradation of the inactive pro-enzyme ( $47 \mathrm{kDa})$ into the active form (37/35 kDa) (Fig. 2B). Furthermore, HSS exhibited a concentration-dependent effect on caspase- 9 activation (Fig. 2C). Similarly, caspase-3 activation, via proteolytic degradation of the $32 \mathrm{kDa}$ pro-enzyme into the $19 / 17 \mathrm{kDa}$ activate form, was detected in the presence of HSS in a concentration-dependent manner (Fig. 2B and C).

HSS regulates apoptosis-related protein expression in BEL-7402 cells. To further investigate the involvement of the HSS-induced apoptotic pathway in BEL-7402 cells, the expression of apoptosis-related proteins: Bax, Bcl-2, cytochrome $c$, PARP and cleaved PARP, was determined by western blot analysis (Fig. 3). BEL-7402 cells treated with HSS for $48 \mathrm{~h}$ exhibited a concentration-dependent upregulation of the proapoptotic protein Bax, as compared with the control group, whereas the anti-apoptotic protein $\mathrm{Bcl}-2$ was downregulated (Fig. 3A and C). The ratio of Bax/Bcl-2 was also significantly 
A

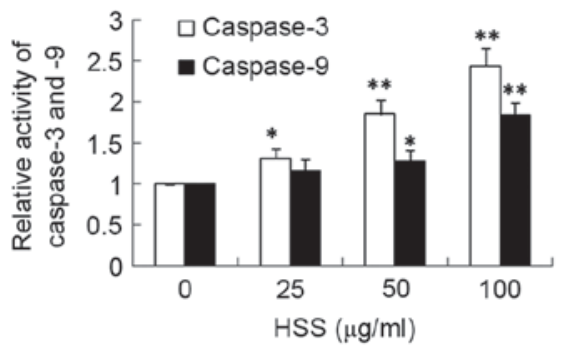

B

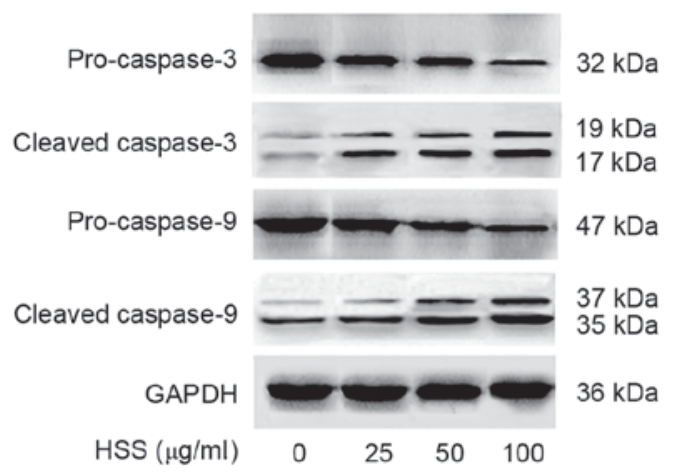

c

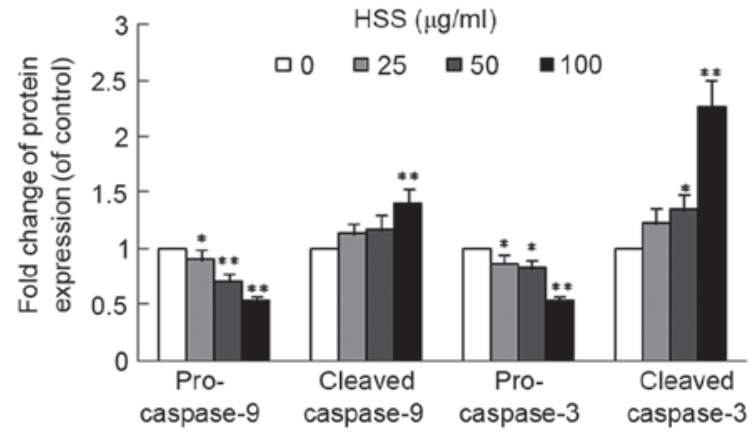

Figure 2. HSS induces caspase activation in hepatocellular carcinoma-derived BEL-7402 cells. (A) Cells were treated with 0, 25, 50 or $100 \mu \mathrm{g} / \mathrm{ml} \mathrm{HSS}$ for $48 \mathrm{~h}$, and the caspase- 3 and caspase- 9 activities were detected using a Caspase Activity kit. (B) Protein levels of pro-caspase-3 and -9 in BEL-7402 cells were determined by western blot analysis and (C) quantified using Quantity One analysis software. GAPDH served as the loading control. Data are presented as the mean \pm standard deviation from three independent experiments. ${ }^{*} \mathrm{P}<0.05$ and ${ }^{* *} \mathrm{P}<0.01$, compared with the control group. HSS, Haishengsu.

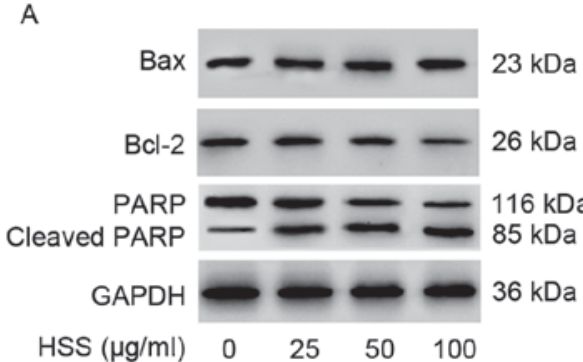

C

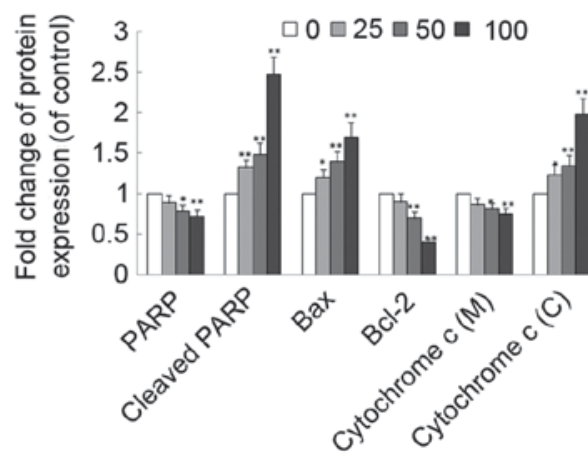

B

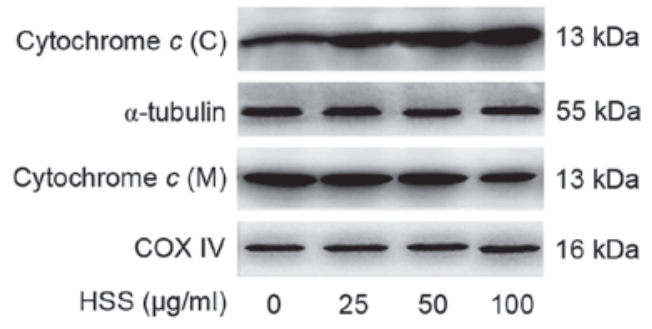

D

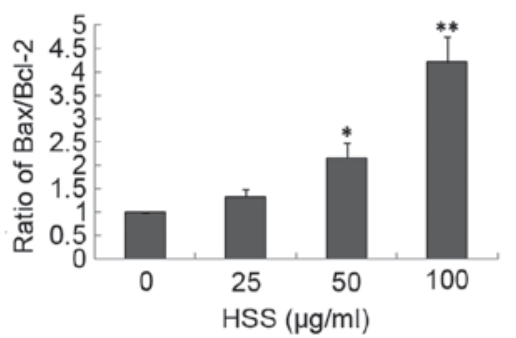

Figure 3. HSS induces alterations in apoptosis-related proteins in hepatocellular carcinoma-derived BEL-7402 cells. BEL-7402 cells were treated with 0, 25, 50 or $100 \mu \mathrm{g} / \mathrm{ml} \mathrm{HSS}$ for $48 \mathrm{~h}$, and western blot analysis was performed on whole cell lysates, and cytosolic and mitochondrial fractions. (A) Expression of Bcl-2, Bax, PARP and cleaved-PARP was analyzed by western blot analysis. GAPDH from the same sample served as the loading control. (B) Cytochrome $c$ localization assay. Cytochrome $c$ was measured in mitochondrial and cytosolic fractions by western blot analysis. COX IV and $\alpha$-tubulin were used as internal controls for the mitochondria and cytosol, respectively. (C) Protein expression levels of Bcl-2, Bax, PARP, cleaved PARP and cytochrome $c$ were quantified using Quantity One analysis software in BEL-7402 cells. (D) Bax/Bcl-2 ratios following treatment with various concentrations of HSS were compared. Data are presented as the mean \pm standard deviation from three independent experiments. ${ }^{*} \mathrm{P}<0.05$ and ${ }^{* *} \mathrm{P}<0.01$, compared with the control group. HSS, Haishengsu; Bcl-2, B-cell lymphoma 2; Bax, Bcl-2-associated X protein; PARP, poly (ADP-ribose) polymerase; COX IV, cytochrome $c$ oxidase IV; C, cytosolic; $\mathrm{M}$, mitochondrial. 
A

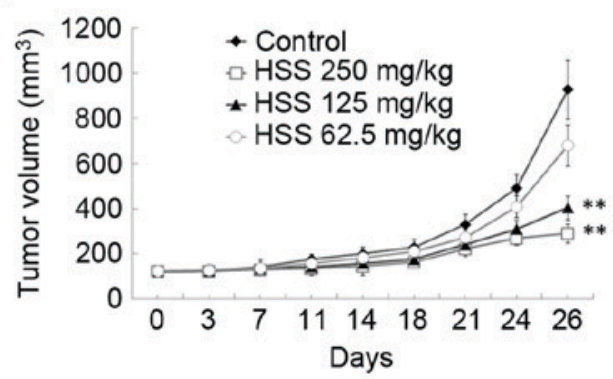

C

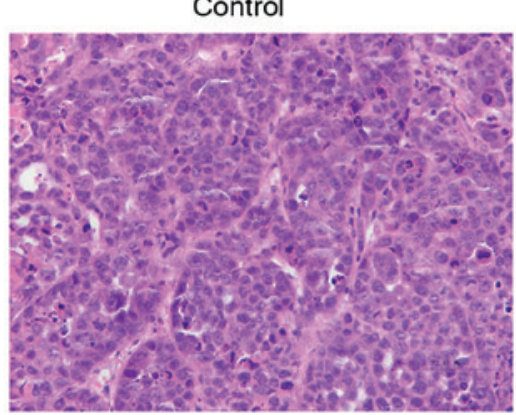

B

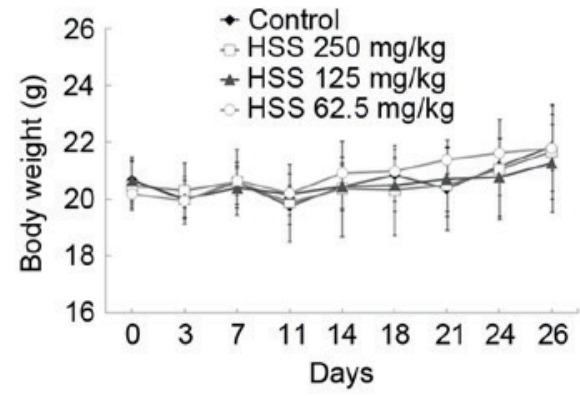

$250 \mathrm{mg} / \mathrm{kg} \mathrm{HSS}$

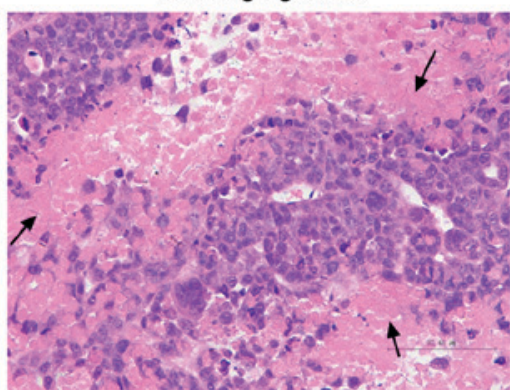

D

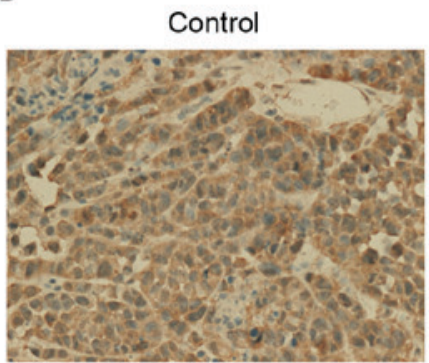

$125 \mathrm{mg} / \mathrm{kg}$ HSS

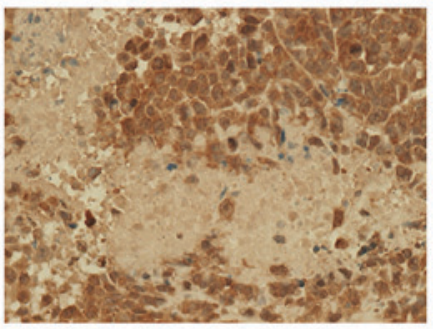

$62.5 \mathrm{mg} / \mathrm{kg} \mathrm{HSS}$

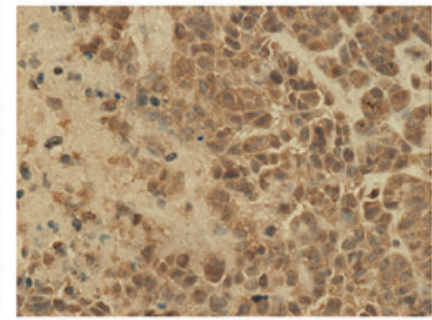

$250 \mathrm{mg} / \mathrm{kg}$ HSS

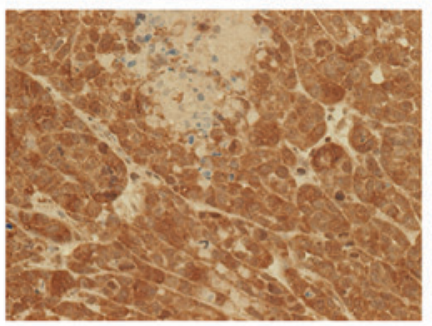

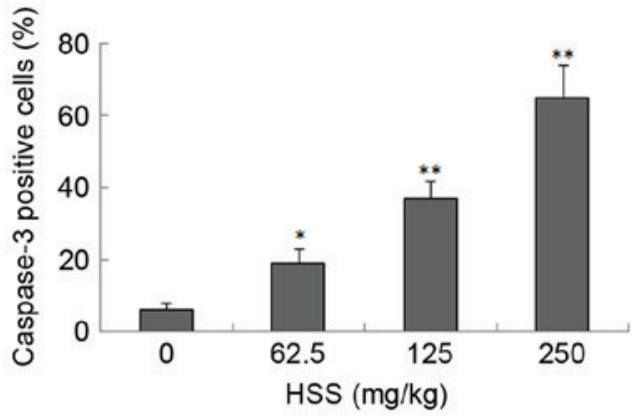

HSS ( $\mathrm{mg} / \mathrm{kg})$

Figure 4. HSS treatment inhibits tumor growth of hepatocellular carcinoma-derived BEL-7402 cell xenografts and induces cell apoptosis in nude mice in vivo. (A) BEL-7402 tumors were established in the flank of mice. The mice were received daily intragastric administrations of $0.5 \%$ sodium carboxymethylcellulose, containing HSS doses of $62.5,125$ or $250 \mathrm{mg} / \mathrm{kg}$, as indicated. (B) Bodyweight of the mice in the control and treatment groups. (C) Tumors were harvested after the mice were sacrificed ( $\mathrm{n}=6 /$ group), and were examined histologically following hematoxylin and eosin staining (magnification, $\mathrm{x} 200$ ). The small arrow indicates the necrotic regions. (D) Cells expressing caspase-3 were counted to calculate the apoptotic index (magnification, x200). Assay was conducted in triplicate. ${ }^{*} \mathrm{P}<0.05$ and ${ }^{* *} \mathrm{P}<0.01$, compared with the control group. HSS, Haishengsu.

increased with HSS treatment (Fig. 3D). Furthermore, cytochrome $c$ was released from the mitochondria to the cytosol; a decrease in the relative density of mitochondrial cytochrome $c$ was observed, with an increase in the relative density of cytosolic cytochrome $c$, at 25, 50 and $100 \mu \mathrm{g} / \mathrm{ml} \mathrm{HSS} \mathrm{(Fig.} \mathrm{3B}$ and C). PARP is a downstream target of active caspase-3 during the induction of the apoptotic signaling pathway, and previous research has indicated that itis cleaved into two fragments (21). HSS was also able to induce PARP cleavage into its active form, as indicated by a reduction in the full-length form $(116 \mathrm{kDa})$ and an increase in the cleaved form $(85 \mathrm{kDa})$ in a concentration-dependent manner (Fig. 3A and C).
HSS administration inhibits tumor growth in nude mice. The effects of HSS on tumor growth were further investigated using a xenograft model. BEL-7402 cells were implanted into the flank of female BALB/c nude mice. The experiment was terminated after 26 days and the tumor size was measured. Tumors in the control group developed faster than the HSS treatment groups, and were $928.9 \pm 131.4 \mathrm{~mm}^{3}$ in size 26 days post-injection (Fig. 4A). HSS administration inhibited tumor growth in a concentration-dependent manner in xenograft nude mice (Fig. 4A). There were no significant differences in overall body weight between the control and the HSS-treated groups (Fig. 4B). Furthermore, H\&E staining revealed an 


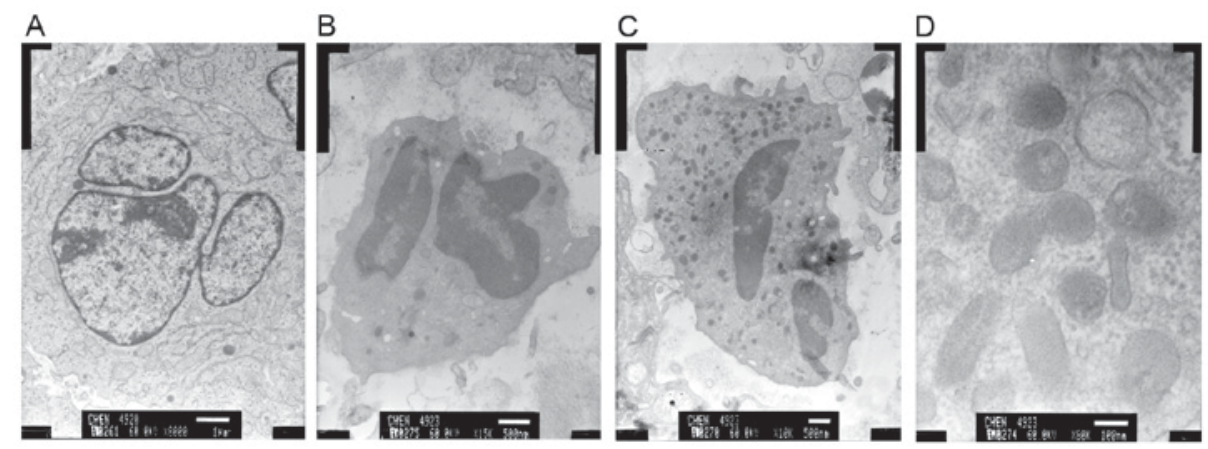

Figure 5. HSS administration alters the cellular ultrastructure in nude mice. Ultrastructural features of BEL-7402 cells induced by HSS were examined using a transmission electron microscope. (A) Control group (magnification, x8,000), (B) HSS group (62.5 mg/kg; magnification, x15,000), (C) HSS group (125 mg/kg; magnification, x10,000), and (D) HSS group (250 mg/kg; magnification, x80,000). HSS, Haishengsu.

increase in necrotic regions in the tumors of HSS treatment groups, compared with the control (Fig. 4C). Histological analysis of liver and kidney samples from both the control and HSS-treated mice revealed no obvious pathological alterations (data not shown), indicating that HSS did not exhibit any strong toxicity.

HSS administration increases apoptosis in nude mice. Caspase-3 expression was investigated in xenograft models by immunohistochemical staining. Treatment with HSS resulted in a significant increase in the proportion of caspase-3-positive cells, in a dose-responsive manner (Fig. 4D). HSS treatment significantly increased the ratio of caspase-3-positive cells by 13,31 and $59 \%$, at concentrations of $62.5,125$ and $250 \mathrm{mg} / \mathrm{kg}$, respectively, compared with the control $(\mathrm{P}<0.05)$.

To further evaluate the effects of HSS on apoptosis, the ultrastructural morphology of xenografts was observed by TEM. Irregular contours of cells and nuclei, nucleolar margination and reduced presence of cytoplasm were observed in the control group (Fig. 5A). Conversely, cells treated with HSS exhibited apoptotic phenomena; the nucleus decreased in size and demonstrated irregular indented edges and variable shape. The karyotheca was crumpled, the karyoplasm was dense and conglomerated, and the chromosomes were condensed and bound to the karyotheca (Fig. 5B and C). Furthermore, the mitochondria were swollen, and the mitochondrial membrane was reduced in thickness or partially ruptured (Fig. 5D). The mitochondrial alterations indicated that the HSS-induced apoptosis in BEL-7402 cells was associated with the mitochondrial-mediated apoptotic pathway.

\section{Discussion}

$\mathrm{HCC}$ is one of the most common malignancies worldwide, with $\sim 630,000$ new cases reported annually (22). Late diagnosis, recurrence and metastasis often result in a poor prognosis for patients with $\mathrm{HCC}$, and the 5-year survival rate of patients undergoing surgical treatment is $<5 \%$ (23). Chemotherapy with conventional cytotoxic agents is often very toxic and insufficiently efficacious (24). Therefore, novel chemotherapeutic agents and more effective therapies for the treatment of $\mathrm{HCC}$ are urgently required.

Natural products may provide promising sources of novel anticancer therapies. The limited side effects of natural products in anticancer therapies has already been recognized, and $>60 \%$ of drugs used to treat cancer are derived from natural sources (25). HSS is a natural extract from T. granosa, which has been used in clinical cancer therapy in China. Our previous research indicated that HSS may induce apoptosis of HCC cells in a concentration-dependent manner, via the Fas signaling pathway (15); however, the mechanisms involved in HSS-induced mitochondrial-mediated apoptosis in HCC cells remain unclear. In the present study, it was observed that HSS effectively induced the apoptosis of BEL-7402 cells via the mitochondrial-mediated pathway in vitro, and inhibited tumor xenograft growth in vivo.

Two major pathways are known to be involved in the regulation of apoptosis, the death receptor (extrinsic) pathway and the mitochondrial-mediated (intrinsic) pathway (26). Increasing evidence has indicated that these two apoptotic pathways are not isolated; crosstalk occurs between them. In the intrinsic pathway, mitochondria are the critical mediators of apoptosis (27-29). Certainstimuli, such as anticancer drugs, can induce permeabilization of the outer mitochondrial membrane and activate the mitochondrial pathway. The present study indicated that HSS treatment may induce the apoptosis of BEL-7402 cells through the intrinsic pathway. HSS treatment promoted the release of cytochrome $c$ into the cytosol, which in turn cleaved and activated caspase-9. This resulted in the activation of caspase-3, as evidenced by an increase in the levels of the cleaved caspase- 3 protein, and a decrease in the pro-caspase-3 form. Following caspase-3 activation, caspase-3 subsequently cleaves PARP into two fragments, and this leads to DNA fragmentation and the induction of apoptosis (29). The present study also demonstrated that HSS was able to induce the cleavage of PARP into its active form, as evidenced by a reduction in the full-length p116 form, and an increase in the cleaved p85 form. In agreement with the findings of the present study, Li et al demonstrated that HSS treatment resulted incaspase- 3 activation and Bcl-2 downregulation in K562/ADM cells, demonstrating that HSS treatment could induce apoptosis in these tumor cells (12). Furthermore, our previous study reported that HSS treatment activated caspase- 8 and upregulated Fas protein and mRNA expression in HCC cells (15), thus suggesting that HSS acts through the extrinsic and the intrinsic apoptotic pathways.

Bcl-2 family proteins regulate the activation of caspases during mitochondrial-mediated apoptosis. The Bcl-2 family of 
proteins consists of anti-apoptotic proteins, such as Bcl-2, and a number of proapoptotic proteins, such as Bax; overexpression of Bcl-2 blocks mitochondrial outer membrane permeabilization and inhibits apoptosis (30). It has been proposed that an agent that could enhance the expression of proapoptotic proteins and/or inhibit the expression of anti-apoptotic proteins may induce apoptosis in cancer cells. Therefore, the balance between Bax and Bcl-2 serves a critical role in the intrinsic pathway of apoptosis (31). Downregulation of $\mathrm{Bcl}-2$ and upregulation of Bax also stimulates the release of cytochrome $c$ from the mitochondria into the cytosol. The present study indicated that HSS treatment upregulated the expression of Bax and downregulated the expression of $\mathrm{Bcl}-2$, leading to an increase in the $\mathrm{Bax} / \mathrm{Bcl}-2$ protein ratio.

In conclusion, the results of the present study indicated that HSS could induce the apoptosis of HCC-derived BEL-7402 cells in vitro and in vivo, via intrinsic apoptotic pathways. These findings may provide the basis for further investigations into the potential clinical effects of T. granosain HCC.

\section{Acknowledgements}

The present study was supported by the National Science Foundation of China Grant (grant no. 81473384).

\section{References}

1. Burgess JG: New and emerging analytical techniques for marine biotechnology. Curr Opin Biotechnol 23: 29-33, 2012.

2. Lin X, Liu M, Hu C and Liao DJ: Targeting cellular proapoptotic molecules for developing anticancer agents from marine sources. Curr Drug Targets 11: 708-715, 2010.

3. Abraham I, El Sayed K, Chen ZS and Guo H: Current status on marine products with reversal effect on cancer multidrug resistance. Mar Drugs 10: 2312-2321, 2012.

4. Gupta SC, Kim JH, Prasad S and Aggarwal BB: Regulation of survival, proliferation, invasion, angiogenesis, and metastasis of tumor cells through modulation of inflammatory pathways by nutraceuticals. Cancer Metastasis Rev 29: 405-434, 2010.

5. Leal MC, Madeira C, Brandão CA, Puga J and Calado R: Bioprospecting of marine invertebrates for new natural products-a chemical and zoogeographical perspective. Molecules 17: 9842-9854, 2012.

6. Hu GP, Yuan J, Sun L, She ZG, Wu JH, Lan XJ, Zhu X, Lin YC and Chen SP: Statistical research on marine natural products based on data obtained between 1985 and 2008. Mar Drugs 9: 514-525, 2011.

7. Li GY, Yu XM, Zhang HW, Zhang B, Wang CB, Xin YC, Yang CZ, Zhou RX and Wang LX: Haishengsu as an adjunct therapy to conventional chemotherapy in patients with non-small cell lung cancer: A pilot randomized and placebo-controlled clinical trial. Complement Ther Med 17: 51-55, 2009.

8. Liu JZ, Chen SG, Zhang B, Wang CB, Zhao XW, Li GY and Wang LX: Effect of haishengsu as an adjunct therapy for patients with advanced renal cell cancer: A randomized and placebo-controlled clinical trial. J Altern Complement Med 15: $1127-1130,2009$

9. Gao MQ, Han YT, Zhu L, Chen SG, Hong ZY and Wang CB: Cytotoxicity of natural extract from Tegillarca granosa on ovarian cancer cells is mediated by multiple molecules. Clin Invest Med 32: E368-E375, 2009.

10. Liu HP, Gao ZH, Cui SX, Xue X, Hou CY, Jiang ZM, Zhao CR, Wang CB, Chen SG and Qu XJ: Haishengsu, a protein from shellfish Tegillarca L. granosa, inhibits the growth and the activity of matrix metalloproteinases-2 and -9 in human lung carcinoma. Food Biophysics 6: 390-396, 2011

11. Li GY, Liu JZ, Zhang B, Yang M, Chen SG, Hou M and Wang LX Tegillarca granosa extract Haishengsu (HSS) suppresses expression of mdr1, BCR/ABL and sorcin in drug-resistant K562/ADM tumors in mice. Adv Med Sci 58: 112-117, 2013.
12. Li GY, Liu JZ, Chen SG, Zhang B, Wang CB and Wang LX: Tegillarca granosa extract Haishengsu inhibits the expression of p-glycoprotein and induces apoptosis in drug-resistant K562/ADM cells. Pharm Biol 48: 529-533, 2010.

13. Xu W, Kong X, Jiang C, Liu X and Xu L: The anti-tumor effect of a polypeptide extracted from Tegillarca granosa Linnaeus on renal metastatic tumor OS-RC-2 cells. Arch Med Sci 11: 849-855, 2015.

14. Li GY, Liu JZ, Chen SG, Wang CB, Bin Z and Wang LX: Effect of a seashell protein Haishengsu on the immunological function of mice with Ehrlich ascites tumor. Immunopharmacol Immunotoxicol 31: 669-674, 2009.

15. Chen X, Han Y,Zhan S, Wang C and Chen S: Tegillarca granosa extract Haishengsu induces apoptosis in human hepatocellular carcinoma cell line BEL-7402 via Fas-signaling pathways. Cell Biochem Biophys 71: 837-844, 2015.

16. Hajra KM and Liu JR: Apoptosome dysfunction in human cancer. Apoptosis 9: 691-704, 2004.

17. Fesik SW: Promoting apoptosis as a strategy for cancer drug discovery. Nat Rev Cancer 5: 876-885, 2005.

18. Khodarev NN, Sokolova IA and Vaughan ATM: Mechanisms of induction of apoptotic DNA fragmentation. Int J Radiat Biol 73: 455-467, 1998

19. Han YT, Chen XH, Gao H, Ye JL and Wang CB: Physcion inhibits the metastatic potential of human colorectal cancer SW620 cells in vitro by suppressing the transcription factor SOX2. Acta pharmacol Sin 37: 264-275, 2016.

20. Ola MS, Nawaz M and Ahsan $\mathrm{H}$ : Role of Bcl-2 family proteins and caspases in the regulation of apoptosis. Mol Cell Biochem 351: 41-58, 2011

21. Lazebnik YA, Kaufmann SH, Desnoyers S, Poirier GG and Earnshaw WC: Cleavage of poly(ADP-ribose) polymerase by a proteinase with properties like ice. Nature 371: 346-347, 1994.

22. Alves RC, Alves D, Guz B, Matos C, Viana M, Harriz M, Terrabuio D, Kondo M, Gampel O and Polletti P: Advanced hepatocellular carcinoma. Review of targeted molecular drugs. Ann Hepatol 10: 21-27, 2011.

23. Jemal A, Bray F, Center MM, Ferlay J, Ward E and Forman D: Global cancer statistics. CA Cancer J Clin 61: 69-90, 2011.

24. Bruix J and Sherman M; American Association for the Study of Liver Diseases: Management of hepatocellular carcinoma: An update. Hepatology 53: 1020-1022, 2011.

25. Newman DJ, Cragg GM and Snader KM: Natural products as sources of new drugs over the period 1981-2002. J Nat Prod 66: 1022-1037, 2003.

26. Indran IR, Tufo G, Pervaiz S and Brenner C: Recent advances in apoptosis, mitochondria and drug resistance in cancer cells. Biochim Biophys Acta 1807: 735-745, 2011

27. Dai JJ, Niu YF, Wu CF, Zhang SH and Zhang DF: Both death receptor and mitochondria mediated apoptotic pathways participated the occurrence of apoptosis in porcine vitrified mii stage oocytes. Cryo Letters 37: 129-136, 2016.

28. Yoo KH, Park JH, Lee DK, Fu YY, Baek NI and Chung IS: Pomolic acid induces apoptosis in SK-OV-3 human ovarian adenocarcinoma cells through the mitochondrial-mediated intrinsic and death receptor-induced extrinsic pathways. Oncol Lett 5: 386-390, 2013.

29. Qi F, Li A, Inagaki Y, Xu H, Wang D, Cui X, Zhang L, Kokudo N, Du G and Tang W: Induction of apoptosis by cinobufacini preparation through mitochondria- and Fas-mediated caspase-dependent pathways in human hepatocellular carcinoma cells. Food Chem Toxicol 50: 295-302, 2012.

30. Elumalai P, Gunadharini DN, Senthilkumar K, Banudevi S, Arunkumar R, Benson CS, Sharmila G and Arunakaran J: Induction of apoptosis in human breast cancer cells by nimbolide through extrinsic and intrinsic pathway. Toxicol Lett 215: 131-142, 2012.

31. Li P, Tian W and Ma X: Alpha-mangostin inhibits intracellular fatty acid synthase and induces apoptosis in breast cancer cells. Mol Cancer 13: 138, 2014. 